\title{
Molecular Cloning and Characterization of $\mathrm{a} \mathrm{Ca}^{2+}+\mathbf{M g}^{2+}$-dependent Adenosine Triphosphatase from Rat Cardiac Sarcoplasmic Reticulum
}

\author{
Regulation of its Expression by Pressure Overload and Developmental Stage \\ Issei Komuro, Masahiko Kurabayashi, Yoshikazu Shibazaki, Fumimaro Takaku, and Yoshio Yazaki \\ Third Department of Internal Medicine, University of Tokyo, 7-3-1 Hongo, Bunkyo-ku, Tokyo, 113 Japan
}

\begin{abstract}
To investigate the regulation of expression of cardiac $\mathrm{Ca}^{2+}$ $+\mathrm{Mg}^{2+}$-dependent ATPase $\left(\mathrm{Ca}^{2+}\right.$-ATPase) in sarcoplasmic reticulum (SR), we isolated cDNA (pHA6) encoding a $\mathrm{Ca}^{2+}$ ATPase of rat cardiac SR. The clone consisted of 2,311 mRNA-derived nucleotides, which covered half the coding region and the entire 3 -untranslated regions. The nucleotides and deduced amino acid sequences of pHA6 showed striking homology, 89 and $98 \%$, respectively, to those of rabbit $\mathrm{Ca}^{2+}$ ATPase of the slow-twitch form. Northern blot analyses revealed that the mRNA levels of $\mathrm{Ca}^{2+}$-ATPase were decreased by pressure overload and became 32\% of sham in 1 mo. During the developmental stage the mRNA levels were very low in the fetal period and steeply increased around birth. These changes in mRNA levels were correlated with the corresponding protein levels. These results suggest that the expression of cardiac $\mathrm{Ca}^{2+}$-ATPase in SR is regulated by pressure overload and the developmental stage, at least in part, at the pretranslational level.
\end{abstract}

\section{Introduction}

Intracellular calcium $\left(\mathrm{Ca}^{2+}\right)$ plays a substantial role in myocardial contraction, and its concentration is determined by the $\mathrm{Ca}^{2+}$ flux across the sarcolemma, together with $\mathrm{Ca}^{2+}$ release and uptake by the intracellular organellas (1). Cardiac sarcoplasmic reticulum (SR) is the major determinant that sequesters intracellular $\mathrm{Ca}^{2+}$ and influences the relaxation and the tension development of myocardium. Calcium uptake by the $\mathrm{SR}$ is driven by $\mathrm{C} \mathrm{Ca}^{2+}+\mathrm{Mg}^{2+}$-dependent ATPase $\left(\mathrm{Ca}^{2+}\right.$-ATPase), ${ }^{1}$ which is a membrane protein with a molecular mass of $100,000 \mathrm{D}$ and constitutes $35-40 \%$ of the protein in cardiac $\operatorname{SR}(2,3)$.

Many changes in mechanical performance and excitationcontraction coupling phenomena have been observed in the

Part of this work was presented at the 60th American Heart Association Scientific Session on 18 November 1987, CA, and was published in abstract form (1987. Circulation. 76(Suppl):IV-476).

Address correspondence to Dr. Issei Komuro, The Third Department of Internal Medicine, Faculty of Medicine, University of Tokyo, 7-3-1 Hongo, Bunkyo-ku, Tokyo, 113, Japan.

Received for publication 9 March 1988 and in revised form 3 November 1988.

1. Abbreviations used in this paper: $\mathrm{Ca}^{2+}-\mathrm{ATPase}, \mathrm{Ca}^{2+}+\mathrm{Mg}^{2+}-\mathrm{de}-$ pendent ATPase; SR, sarcoplasmic reticulum; TES, $N$-tris(hydroxymethyl)methyl-2-aminomethane-sulfonic acid.

J. Clin. Invest.

(c) The American Society for Clinical Investigation, Inc.

0021-9738/89/04/1102/07 \$2.00

Volume 83, April 1989, 1102-1108 hypertrophied heart. In cardiac hypertrophy induced by pressure overload, there is a decrease in the maximal velocity of shortening and in peak isometric tension development, and a prolonged duration of isometric contraction and time-to-peak tension $(4,5)$. Abnormalities of the diastolic properties of the left ventricle, especially diastolic relaxation and compliance, also exist under cardiac hypertrophy (6-8). The decreased velocity of shortening could be explained by the isozymic transition of cardiac myosin (9), whereas prolonged duration of isometric contraction and a decrease in peak isometric tension development were thought to be due to impaired $\mathrm{Ca}^{2+}$ handling. Since a prolonged duration of isometric contraction in the hypertrophied muscles correlated with a similar prolongation of the calcium transient, Gwathmey and Morgan thought that the rate of sequestration and perhaps release of $\mathrm{Ca}^{2+}$ by intracellular stores is decreased in hypertrophy (10). Many studies have shown the depression in $\mathrm{Ca}^{2+}$ uptake and $\mathrm{Ca}^{2+}$ ATPase of SR in hypertrophied hearts (11-13); however, there have been quite a few reports concerning the mRNA levels of $\mathrm{Ca}^{2+}$-ATPase. In addition, although it is generally accepted that there are many differences in myocardial function between fetus and adult (14), developmental regulation of the cardiac $\mathrm{Ca}^{2+}$-ATPase of SR remained unclear.

Recently, MacLennan et al. have cloned and sequenced cDNA encoding a $\mathrm{Ca}^{2+}$-ATPase of rabbit skeletal muscle SR (15-17). In the present study, to know the regulation of expression of cardiac $\mathrm{Ca}^{2+}$-ATPase, we have isolated and characterized the cDNA encoding a $\mathrm{Ca}^{2+}$-ATPase of rat cardiac SR, and using the cDNA as a probe we investigated its expression in hearts during hypertrophy and development at the mRNA level. In addition, we prepared SR fractions and examined the changes of $\mathrm{Ca}^{2+}$-ATPase content and $\mathrm{Ca}^{2+}$ uptake at the protein level.

\section{Methods}

Screening of the rat heart cDNA library. Rat cardiac $\mathrm{Ca}^{2+}$-ATPase cDNA was identified from the Sprague-Dawley rat heart cDNA library, purchased from Clontech Laboratory Inc., Palo Alto, CA., by the phage plaque hybridization method. In brief, the library was screened with Pst I/Pst I restriction fragment of rabbit $\mathrm{Ca}^{2+}$-ATPase cDNA plasmid (15), which was a generous gift from Dr. MacLennan, University of Toronto, Toronto, $\mathrm{ON}$, as a probe. Probes were prepared by using the random-priming procedures. Phages were plated at a density of $1.5 \times 10^{4} / 150-\mathrm{mm}$ plate, and plaques were transferred to nitrocellulose filters. Approximately $1.5 \times 10^{5}$ plaques were screened with the ${ }^{32} \mathrm{P}$-labeled $\mathrm{cDNA}$ probe. Hybridization with ${ }^{32} \mathrm{P}$-labeled cDNA $\left(1 \times 10^{7} \mathrm{cpm} / \mathrm{ml}\right)$ was performed at $42^{\circ} \mathrm{C}$ for $24 \mathrm{~h}$ in a solution containing $40 \%$ (vol/vol) formamide, $2 \times$ standard saline citrate (SSC) ( $1 \times \mathrm{SSC}$ is $150 \mathrm{mM} \mathrm{NaCl}, 15 \mathrm{mM}$ sodium citrate), $5 \times$ Denhardt's solution ( $1 \times$ Denhardt's solution is $0.02 \%$ Ficoll, $0.02 \%$ polyvinylpyrrolidone, and $0.02 \% \mathrm{BSA}$ ), $0.1 \% \mathrm{SDS}, 1 \mathrm{mM}$ EDTA, and $100 \mu \mathrm{g} / \mathrm{ml}$ salmon sperm DNA. Filters were washed to a stringency of $0.1 \times \mathrm{SSC}$, 
$0.1 \%$ SDS at $42^{\circ} \mathrm{C}$, and exposed for $24 \mathrm{~h}$ at $-70^{\circ} \mathrm{C}$ to XAR-5 film (Eastman Kodak Co., Rochester, NY). Positive recombinant phages were purified by sequential screening at low plaque density. Phage DNA was purified according to Maniatis et al. (18). Eco RI-excised cDNA inserts were subcloned into a plasmid vector pUC13 and characterized by restriction endonuclease mapping.

$c D N A$ sequence analysis. Appropriate restriction fragments were isolated from agarose gels and subcloned either into bacteriophage M13 or plasmid vector pUC19. DNA sequencing was performed by the dideoxynucleotide chain-termination method of Sanger et al. (19).

Animals and surgical procedures. To make pressure overload-induced hypertrophy, male Wistar rats (40 d old, weighing 150-180 g) were anesthetized with diethyl ether and the upper part of the abdominal aorta was constricted with a hemoclip. Of 204 operated rats, 158 survived the procedures and were killed at predetermined times after the operation $(0.5,2,4,8,12,24,48$, and $72 \mathrm{~h}, 1 \mathrm{wk}$, and $1 \mathrm{mo} ; n=16$, $18,16,18,14,18,15,13,15$, and 15 , respectively). Sham-operated animals underwent identical procedures except for placement of the hemoclip and were killed after different time intervals postoperatively. To investigate the developmental change, hearts of 12-, 15-, and 18-d embryos, 5-d-old neonates, and 40- and 200-d-old adults were examined.

$R N A$ preparation. The body weight was measured and the hearts were excised. The atria, great vessels, and right ventricular free walls were removed. The left ventricles were opened, rinsed with cold saline, weighed, and quickly frozen in liquid nitrogen. Total cellular RNA was extracted from three or four left ventricles by the lithium urea method (20). Poly $\left(\mathrm{A}^{+}\right)$RNA was enriched by oligo(dT)-cellulose chromatography. Total RNA was also extracted from soleus and hindlimb muscles of 40-d-old rats.

Northern blot analysis. $20 \mu \mathrm{g}$ of total RNA or $3 \mu \mathrm{g}$ of poly $\left(\mathrm{A}^{+}\right) \mathrm{RNA}$ was denatured at $60^{\circ} \mathrm{C}$ for $7 \mathrm{~min}$, fractionated by electrophoresis through $1.2 \%$ agarose gels, and transferred to nylon membrane. Membranes were exposed to ultraviolet rays for $2.5 \mathrm{~min}$, prehybridized, and hybridized at $42^{\circ} \mathrm{C}$ with ${ }^{32} \mathrm{P}$-labeled cDNA probe. Prehybridization was performed in a solution containing $40 \%$ formamide, $5 \times \operatorname{SSPE}(0.9$ $\mathrm{M} \mathrm{NaCl}, 40 \mathrm{mM} \mathrm{NaOH}, 50 \mathrm{mM} \mathrm{Na}_{2} \mathrm{HPO}_{3}, 5 \mathrm{mM}$ EDTA) buffer, $5 \times$ Denhardt's solution, $1 \%$ SDS, $10 \%$ dextran sulfate, and $100 \mu \mathrm{g} / \mathrm{ml}$ of heat-denatured salmon sperm DNA for $24 \mathrm{~h}$ at $42^{\circ} \mathrm{C}$. Hybridization was performed in the same solution with the addition of $5 \times 10^{7}$ $\mathrm{cpm} / \mathrm{ml}$ of ${ }^{32} \mathrm{P}$-labeled probe for $24 \mathrm{~h}$ at $42^{\circ} \mathrm{C}$. Membranes were washed twice at $42^{\circ} \mathrm{C}$ with $2 \times$ SSC and $0.1 \%$ SDS and twice at $42^{\circ} \mathrm{C}$ with $0.2 \times$ SSC and $0.1 \%$ SDS, air dried, and exposed to $x$-ray film for $24 \mathrm{~h}$ at $-70^{\circ} \mathrm{C}$ with intensifying screen. Relative amounts of $\mathrm{Ca}^{2+}$. ATPase expression were determined by a densitometric scanner. Control hybridizations were carried out using a $1.1-\mathrm{kb}$ mouse $\alpha$-actin cDNA (21).

Isolation of SR, gel electrophoresis, and assay of $\mathrm{Ca}^{2+}$ uptake. SR was isolated using a method of Nakanishi and Jarmakani (14). Eighty 15-d-old fetal hearts, four 40-d-old adult hearts that received pressure overload for $2 \mathrm{wk}$ or $1 \mathrm{mo}$, and four sham-operated hearts were used for SR isolation. The left ventricles were minced with scissors and homogenized three times with a polytron tissue processor at a setting of 2 for $5 \mathrm{~s}$ in $4 \mathrm{vol}$ of the isolation solution containing $10 \mathrm{mM} \mathrm{Na}_{2} \mathrm{HCO}_{3}$ (pH 7.1 with $0.1 \mathrm{~N} \mathrm{HCl}$ ). The homogenate was centrifuged at $1,000 \mathrm{~g}$ for $10 \mathrm{~min}$. The supernatant was centrifuged at $14,000 \mathrm{~g}$ for $20 \mathrm{~min}$ three times to remove mitochondria. The supernatant from the third spin was centrifuged at $45,000 \mathrm{~g}$ for $30 \mathrm{~min}$. The pellet was suspended in a solution containing $0.6 \mathrm{M} \mathrm{KCl}$ and $10 \mathrm{mM} N$-tris(hydroxymethyl)methyl-2-aminomethane-sulfonic acid (TES; pH 7.1) using a glass-Teflon homogenizer. The suspension was centrifuged at $45,000 \mathrm{~g}$ for $30 \mathrm{~min}$. The resulting pellet was suspended in solution containing $150 \mathrm{mM} \mathrm{KCl}$ and $1 \mathrm{mM}$ TES (pH 7.1) and used as SR fractions. The SR fractions were separated by electrophoresis with $7.5 \%$ acrylamide according to the procedure of Laemmli (22) and stained with Coomassie blue. The density of the protein band corresponding to the 100,000-D Ca ${ }^{2+}$-ATPase protein was measured by a densitometric scanner. $\mathrm{Ca}^{2+}$ uptake by SR was measured by the Millipore technique

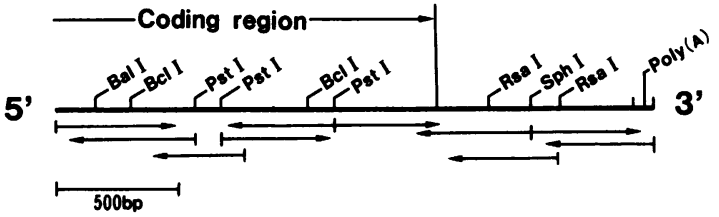

Figure 1. Restriction map and sequencing strategy for the cDNA insert of clone pHA6. The extent and direction of sequencing are indicated by the arrows. Sequence was determined by the dideoxy methods.

as in Ito et al. (13) at $25^{\circ} \mathrm{C}$ in buffer containing $10 \mathrm{mM}$ Tris-histidine (pH 7.2), $5 \mathrm{mM} \mathrm{MgCl}, 100 \mathrm{mM} \mathrm{KCl}, 5 \mathrm{mM}$ sodium azide, $5 \mathrm{mM}$ sodium oxalate, $50 \mu \mathrm{M} \mathrm{CaCl}_{2}, 50 \mu \mathrm{g}$ of $\mathrm{SR}$ protein, and $5 \mathrm{mM}$ sodium ATP. $\mathrm{Na}^{+}-\mathrm{K}^{+}$-ATPase activity and cytochrome $c$ oxidase activity were measured as marker enzymes by the method of Bers (23) and Wharton and Tzagoloff (24), respectively.

\section{Results}

Isolation of rat cardiac $\mathrm{Ca}^{2+}-\mathrm{ATPase}$ clones. Approximately 110 positive clones were identified from among $\sim 1.5 \times 10^{5}$ recombinant phages. The Eco RI-digested fragments from nine of these clones were subcloned into the Eco RI restriction site of plasmid pUC13. These clones contained long inserts $(>1,800 \mathrm{bp})$ and had the same restriction maps in regions where they overlapped. Then two clones, designated pHA6 and $\mathrm{pHA} 12$, were subjected to sequencing.

Restriction mapping and sequence analysis of pHA6 clone. Fig. 1 shows a restriction endonuclease cleavage map and sequence strategy for the pHA6 clone. Nucleotide and deduced amino acid sequences are shown in Fig. 2. Clone pHA6 consists of 2,311 mRNA-derived nucleotides, which encode half the amino acid of $\mathrm{Ca}^{2+}$-ATPase, including the entire $3^{\prime}$-untranslated region and a portion of the poly $\left(\mathrm{A}^{+}\right)$tail. Clone pHA 12 consists of 2,166 mRNA-derived nucleotides, and they were identical to those of the pHA6 clone. Fig. 3 shows the amino acid comparison between the pHA6 clone and rabbit skeletal $\mathrm{Ca}^{2+}$-ATPase clones. The extensive homology was recognized between pHA6 and rabbit slow-twitch skeletal $\mathrm{Ca}^{2+}$ ATPase (pCA4; 15). In coding regions, $89 \%$ of the nucleotide positions were identical and the corresponding amino acid positions for this region showed $98 \%$ homology. Furthermore, even in the untranslated regions, there was high homology between cardiac and slow-twitch skeletal $\mathrm{Ca}^{2+}$-ATPase, in spite of the species difference. Alignment of DNA sequences to obtain maximum homology reveals $88 \%$ homology. In contrast, degree of the homology was relatively low between cardiac and fast-twitch skeletal $\mathrm{Ca}^{2+}$-ATPase clones (pFA4; 16). Direct comparison of the DNA sequences of clones pHA6 and pFA4 demonstrates $80 \%$ nucleotide and $81 \%$ amino acid homology within the translated regions. More numerous nucleotide mismatches were observed within the 3'-untranslated region and at least $35 \%$ nucleotides were divergent.

Northern blot hybridization analysis of rat muscle mRNA. Fig. $4 A$ shows Northern blots of adult rat skeletal and cardiac muscle RNA hybridized with the Pst I-Pst I restriction fragment (nucleotide residues 607-1,156) from the coding region of the clone pHA6. The hybridizations were observed with a higher mol wt transcript in cardiac muscle and with the lower mol wt transcript in the hindlimb muscle. Two messages of different sizes bound the probe in the soleus muscle, which 
* 1
TCA. CGT. GAT. CGA. AAA. TCA. ATG. TCC.GTC. TAC. TGT. ACA. CCA. AAC. AAA. CCG.AGC. CGG. ACG. TCC
Ser-Arg-Asp-Arg-LYS-Ser-Met-Ser-Val-TYr-CYS-Thr-Pro-Asn-Lys-Pro-Ser-Arg-Thr-Ser * 61 ATG. AGC. AAG. ATG. TTT.GTG. AAG.GGT.GCT. CCA.GAA.GGT.GTC. ATC. GAC. AGG.TGC. ACC. CAC. ATC * 121 1(0)* CGA.GTT. GGA.AGT. ACC.AAG.GTC. CCC. ATG. ACG. GCT. GGT.GTT. AAA. CAG. AAG. ATT. ATG.TCT. GTC
Arg-Val-Gly-Ser-Thr-Lys-Val-Pro-Met-Thr-Ala-Gly-Val-Lys-Gln-Lys-Ile-Met-Ser-Val * 181 240* ATT. CGG.GAG. TGG.GGC.AGT. GGC. AGC. GAC. ACA. CTG. CGG.TGC.CTG. GCT. CTG. GCC. ACT. CAT. GAC
Ile-Arg-Glu-TrP-Gly-Ser-Gly-Ser-Asp-Thr-Leu-Arg-Cys-Leu-Ala-Leu-Ala-Thr-His-Asp

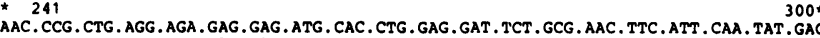
Asn-Pro-Leu-Arg-Arg-Glu-Glu-Met-His-Leu-Glu-Asp-Ser-Ala-Asn-Phe-Ile-Gln-Tyr-Glu * 3010360

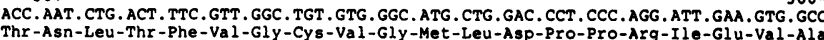
TCT.TCT.GTG.AAG.CTG.TGC. CGG. CAA.GCG.GCC. ATC. CGA.GTC. ATC. ATG. ATC. ACT.GGG.GAT. AAC Ser-Ser-Val-Lys-Leu-Cys-Arg-Gln-Ala-Ala-Ile-Arg-Val-Ile-Met-Ile-Thr-Gly-Asp-As * 421 AAA.GGC. ACT. GCT. GTG.GCC. ATC. TGT. CGC. CGC.ATT.GGC. ATC. TTT. GGG. CAG. GAT. GAG.GAT. GTG
LYs-Gly-Thr-Ala-Val-Ala-Ile-CYs-Arg-Arg-Ile-Gly-Ile-Phe-Gly-GIn-Asp-GIU-ASP-Val * 481 aca 540 Thr-Ser-Lys-Ala-Phe-Thr-Gly-Arg-Glu-Phe-Asp-Glu-Leu-Ser-Pro-Ser-Ala-Gln-AGA.GAC

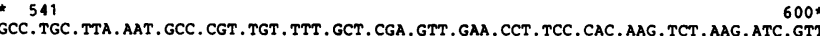
Ala-Cys-Leu-Asn-Ala-Arg-Cys-Phe-Ala-Arg-Val-Glu-Pro-Ser-His-Lys-Ser-Lys-Ile-Va

GAG.TTC. CTG. CAG. TCC. TTT. GAT.GAG. ATC. ACA. GCT. ATG.ACT.GGT.GAT. GGT.GTG. AaC.GAC.GCC Glu-Phe-Leu-GIn-Ser-Phe-Asp-Glu-Ile-Thr-Ala-Met-Thr-Gly-Asp-Gly-Val-Asn-Asp-Ala * 661 CCC. GCT. CTG. AAG. AAG.TCG.GAA.ATC.GGG. ATT. GCC.ATG. GGC.TCA.GGG. ACT.GCA.GTG. GCT. AAC

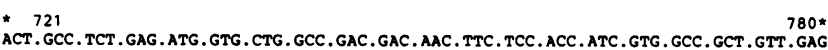
ACT.GCC.TCT.GAG.ATG.GTG.CTG.GCC.GAC. GAC.AAC.TTC.TCC. ACC.ATC. GTG. GCC. GCT. GTT. GAG
Thr-Ala-Ser-Glu-Met-Val-Leu-Ala-Asp-Asp-Asn-Phe-Ser-Thr-Ile-Val-Ala-Ala-Val-Glu * 781
GAG. GGG. CGC.GCC. ATC. TAC. AAC. AAC. ATG. AAG. CAG. TTC. ATC. CGC.TAC.CTC. ATC. TCC. TCC. AAC
$840 *$ Glu-Gly-Arg-Ala-Ile-Tyr-Asn-Asn-Met-Lys-Gln-Phe-Ile-Arg-Tyr-Leu-Ile-Ser-Ser-Asn GTG.GGG.GAG.GTG.GTC.TGT.ATC.TTC.CTG.ACG.GCA.GCC. CTT.GGG.TTT.CCT.GAG.GCT.TTG.ATT GTG. GGG.GAG.GTG.GTC.TGT. ATC. TTC. CTG. ACG. GCA.GCC.CTT. GGG.TTT. CCT.GAG. GCT. TTG.ATT
Val-Gly-Glu-Val-Val-CYs-Ile-Phe-Leu-Thr-Ala-Ala-Leu-Gly-Phe-Pro-Glu-Ala-Leu-Ile * 901 1 960

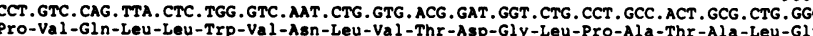

Figure 2. Nucleotide sequence and deduced amino acid sequence of clone pHA6. The nucleic acids are numbered beginning at the first triplet of the cloned $\mathrm{Ca}^{2+}$-ATPase sequence.

consists of both slow-twitch fibers and fast-twitch fibers. The mRNA level of the cardiac $\mathrm{Ca}^{2+}$-ATPase was slightly less than those of the skeletal $\mathrm{Ca}^{2+}$-ATPase. In contrast, Northern blot analysis revealed that a cDNA probe from the 3 -untranslated region, Sph I-Eco RI fragment, of pHA6 hybridized only to the higher mol wt transcript in both soleus and cardiac muscle but

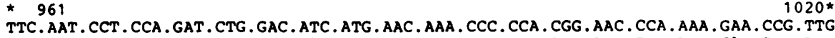
Phe-Asn-Pro-Pro-Asp-Leu-Asp-Ile-Met-Asn-Lys-Pro-Pro-Arg-Asn-Pro-Lys-Glu-Pro-Leu $* 1021$ ATC. AGC.GGG.TGG.CTC. TTT. TTC. CGT. TAC. CTG. GCT. ATT.GGC.TGT. TAT.GTT. GGC. GCT. GCC.ACC 1081 . 1140 \begin{tabular}{l} 
* 1081 \\
GTG.GG'.GCT.GCT.GCG.TGG.TGG.TTC. ATC.GCT.GCT.GAC.GGT.GGT. CCG. AGA.GTC. TCC. TTC. TAC \\
$1110 *$ \\
\hline
\end{tabular} Val-Gly-Ala-Ala-Ala-Trp-Trp-Phe-Ile-Ala-Ala-Asp-Gly-Gly-Pro-Arg-Val-Ser-Phe-Ty

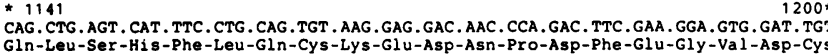
$1200 *$
CAG.CTG.AGT. CAT.TTC.CTG.CAG.TGT. AAG.GAG.GAC. AAC.CCA.GAC.TTC.GAA.GGA.GTG.GAT. TGT
Gln-Leu-Ser-His-Phe-Leu-GIn-CYs-LYs-Glu-Asp-Asn-Pro-Asp-Phe-Glu-Gly-Val-Asp-CYS $\star 1201$ GCA.ATC. TTT. GAG. TCC. CCG. TAT. CCG. ATG. ACA. ATG. GCA.CTT. TCT. GTT. CTA.GTC. ACC. ATA.GAG
Ala-Ile-Phe-Glu-Ser-Pro-Tyr-Pro-Met-Thr-Met-Ala-Leu-Ser-Val-Leu-Val-Thr-Ile-Glu * 1261 1320* ATG.TGC. AAT. GCC. CTC. AAC. AGC.TTG.TCT. GAA. AAC. CAG. TCC. CTG. CTG. AGG. ATG. CCC. CCC. TGG Met-Cys-Asn-Ala-LeU-Asn-Ser-Leu-Ser-Glu-Asn-GIn-Ser-Leu-Leu-Arg-Met-Pro-Pro-Tr * 1321

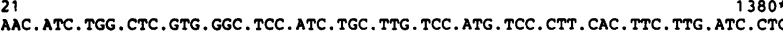
Glu-Asn-Ile-Trp-Leu-Val-Gly-Ser-Ile-Cys-Leu-Ser-Met-Ser-Leu-His-Phe-Leu-Ile-Leu * 1381 Tyr-Val-Glu-Pro-Leu-Pro-Leu-Ile-Phe-Gln-Ile-Thr-Pro-Leu-Asn-Leu-Thr-Gln-Trp-Leu * 1441 1500 Met-Val-Leu-Lys-Ile-Ser-Leu-Pro-Val-Ile-Leu-Met-Asp-Glu-Thr-Leu-Lys-Phe-VTG. GC * 1501 CGA.AAC.TAC. CTG.GAG.CCT.GCA.ATA.CTG.GAG.TAACCGCTTCCTAAACATGCAGAAATGTAAGGGTTTCG
Arg-Asn-TyY-Leu-Glu-Pro-Ala-Ile-Leu-Glu

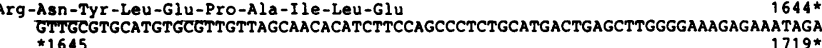
ACAGCCCCCAGCTCACTGTGTGATGTGGAGGAAATGTGTATTACAAGTGGGGTTTTAGCTGTGAGTCAAAATAAT
\$1794* \$1720
AACAAGTTACAATTTAGCATAAGGAATCGGAGAGCCTCTCCAGAGAAGTCGGTTTCTTTGCTGCAAGAAGAATC
1794

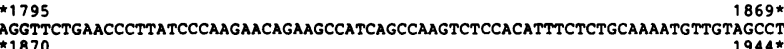
CTATAACTGTATGATAGTGTAATGCATGCCTTCAGTTGTAAGTGGCCAGATCGCGCTTACAGTGACATTGAAACC

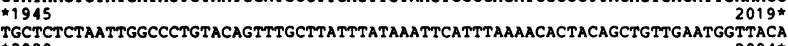
ACCTAGGCCTCCGGTCCTAACTTCAAGTGTTCTCCTCGGTGTGCAGCCAGCTGTTCCCACACTGTATTATTGTAa CTTATTTAGTGAaGTCAGAaGCAGTAGGACAGATGTTGgTGGCAATACAAGTATTGTGTGCATTTATCGTAATA AGTCGTCCGCGTCGGTTCAGTTCCTCACAGCTTCTCACAGTGCATGTCTGACTGTAGTCTGTAAATAGAGGTCA TGTCCGTGCTGCTAACAGGTATCGATCGCACAGACATGATTTCAGGTAAATAAATCGATTCTACGAT-POlY (A)

did not hybridize to mRNA in hindlimb muscle or to the lower mol wt transcript in soleus muscle (Fig. 4 B).

Northern blot hybridization analysis of $\mathrm{Ca}^{2+}-$ ATPase in pressure overload-induced hypertrophy. The mean aortic pressure in the aortic-constricted animals showed an increase of $46 \pm 6 \mathrm{mmHg}$ after $4 \mathrm{~h}(n=4)$ and $62 \pm 6 \mathrm{mmHg}$ after $1 \mathrm{mo}(n$
PHA $:$ SRDRKSMSVYCTPNKPSR TSMSKMFVKGAंPEGVIDRCTHIRVGSTKVPMTAGVKQKIMSVIREWGSGSD 70 PCA 4: SRDRKSMSVYCTPNKPSR TSMSKMFVKGAPEGVIDRCTH IRVGSTKVPMTAGVKOKIMSVIREWGSGSD

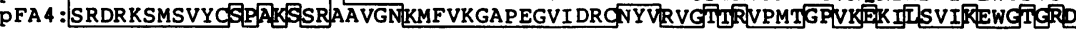

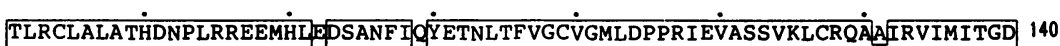
TLRCLALATHDNPLRREEMHL SSANFI I KTTNLTFVGCVGMLDPPRIEVASSVKLCROAGIRVIMITGD

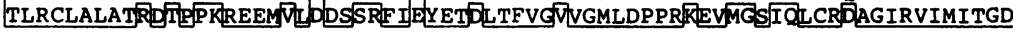
NKGTAVAICRR IGIFGQDEDVTTSKAFTGREFDELSPSAQRDACLNARCFAंRVEPSHKSKIVEFLQSFDEI 210 NKGTAVAICRRI IFGO FEDVTALAFTGREFDELNPSAQRDACLNARCFARVEP SHKSKIVEFLQSFDEI

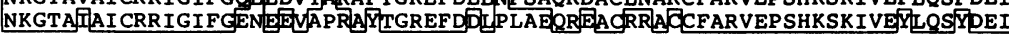

TAMTGDGVNDAPALKKSEIGं IAMGSGTAVAKTASEMVLADDNFST IVAAVEEGRAIYNNMKKQFIRYLISS 280 TAMTGDGVNDA PALKKAEIGIAMGSGTAVAKTASEMVLADDNFSTIVAAVEEGRAIYNNMKOF IRYLISS TAMTGDGVNDAPALKKAEIGIAMGSGTAVAKTASEMVLADDNFSTIVAAVEEGRAIYNNMKQFIRYLISS

NVGEVVCIFLTTAALGFPEALIIPVQLLWVNLVTDGLPATALGFNPPDLDIMNKPPRNPKEPLISGWLFFRY 350 NVGEVVCIFL TAALGFPEALIPVQLLWVNLVTDGLPATALGFNPPDLDIMNKPPRNPKEPLISGWLFFRY NVGEVVCIFLTAALGIPEALIPVQLLWVNLVTDGLPATALGFNPPDLDIMDRPPRSPKEPLISGWLFFRY

LAIGCYVGAATVGAAAWWF I IAADGGPRVSFYYQLSHFLQCKEDNPDFEGVDCAIFESPYPMTMALSVLVTI 420 LAIGCYVGAATVGAAAWWFIAADGGPRVSF YQLSHFLQCKEDNPDFEGVDCAIFES PYPMTMALSVLVT

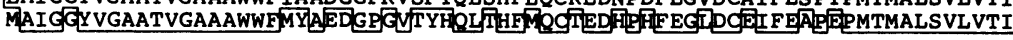

EMCNALNSLSENQSLLRMPPंWENIWLVGSICLSMSLHFLILYVEPLPLIF்ITPLNLTQWंLMVLKISLPV 490 EMCNALNSLSENQSLLRMP PWEN IWLVGS ICLSMSLHFL IL YVEPLPLIFQITPLNVTQWLMVLKISLPV EMCNALNSLSENQSL RRMPPWWWIWLIGSICLSMSLHFLIL Y DPPLPMIFKLKALDLTQWLMVLK ISLPV

ILMDETLKFVंARNYLEPAILE *

ILMDETLKFVARNYLEPAILE *
Figure 3. Amino acid sequence homology among the rat cardiac and the rabbit slowand fast-twitch skeletal muscle forms of the $\mathrm{Ca}^{2+}$-ATPase. The amino acid sequence of the rat cardiac $\mathrm{Ca}^{2+}$-ATPase of SR (pHA6) was compared with those of the rabbit slow(pCA4) and fast-twitch (pFA4) skeletal $\mathrm{Ca}^{2+}$. ATPase $(15,16)$. The sequence of the cardiac and slow $\mathrm{Ca}^{2+}$-ATPase is shifted to the right by one residue at residue 19 to allow realignment after the difference in sequence length. Identical amino acids are boxed. 


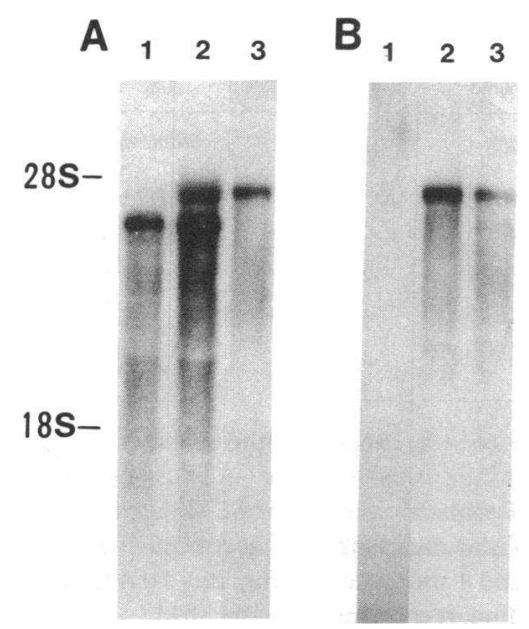

Figure 4. Northern blot analysis of rat muscle mRNA. The coding region, Pst I-Pst I restriction fragment $(A)$, and the untranslated region, Sph I-Eco RI restriction fragment $(B)$, of the pHA6 clone were hybridized with the rat muscle RNA. The same filter was probed sequentially for $A$ and $B$. Each lane contained 20 $\mu \mathrm{g}$ of total RNA from hindlimb (I), soleus (2), and cardiac muscle (3), respectively. The size of rRNA is indicated as a marker.

$=4)$, compared with the sham controls $(n=4)$. The cardiac hypertrophy was already evident at $72 \mathrm{~h}$ after the operation. The percent hypertrophy score (mean experimental left ventricular weight - mean sham-operated left ventricular weight)/mean sham-operated left ventricular weight, was $29 \%$ at $72 \mathrm{~h}$ after the operation, and 59\% hypertrophy was observed 1 mo after aortic constriction. The mRNA levels of cardiac $\mathrm{Ca}^{2+}$-ATPase were markedly decreased by pressure overload compared with sham controls (Fig. $5 \mathrm{~A}$ ). Sham operation did not change the mRNA levels of $\mathrm{Ca}^{2+}$-ATPase (data not shown). The decrease was first detected at $4 \mathrm{~h}$ after the operation, gradually progressed to $72 \mathrm{~h}$, and after that the lower level of the expression was continued. By densitometer scanning the mRNA level at $4 \mathrm{~h}$ was $82 \pm 5 \%$ (mean \pm SEM, $P<0.05)$, and at 1 mo it was $32 \pm 7 \%(P<0.001)$ compared with sham (Fig. 5 $B)$. The mRNA levels of $\mathrm{Ca}^{2+}$-ATPase in the hindlimb muscle did not change in the same pressure-overload conditions (Fig. 5 C).

Northern blot hybridization analysis of $\mathrm{Ca}^{2+}-\mathrm{ATPase}$ during development. Fig. $6 \mathrm{~A}$ shows Northern blots of rat cardiac muscle mRNA of different developmental stages hybridized with the Eco RI-Eco RI 2.3-kb fragment. The expression level of $\mathrm{Ca}^{2+}$-ATPase was significantly low during the early embryonic period, and from $2 \mathrm{~d}$ before birth it was steeply increased. The mRNA levels in 12-d fetuses and 5-d neonates were $8 \pm 3 \%$ and $82 \pm 9 \%$, compared with 200 -d-old adults by densitometer scanning (Fig. 6 B).

Gel electrophoretic analysis of $S R$ and assay of $\mathrm{Ca}^{2+}$ uptake. The yield of the SR protein in the fetus was significantly less than in the adult $(0.12 \pm 0.08 \mathrm{mg} / \mathrm{g}$ in fetus vs. $0.84 \pm 0.10$ $\mathrm{mg} / \mathrm{g}$ in $40-\mathrm{d}$-old adult, $P<0.01$ ) and that in the hypertrophied hearts was similar to the sham-operated hearts ( 2 wk after the operation, $0.89 \pm 0.10 ; 1 \mathrm{mo}, 0.94 \pm 0.16$; sham, $0.90 \pm 0.12 \mathrm{mg} / \mathrm{g}) . \mathrm{Na}^{+}-\mathrm{K}^{+}$-ATPase activity and cytochrome $c$ oxidase activity in the SR fraction were $<1 \%$ of the total activities and were similar in all groups. PAGE of the SR fraction isolated from the hypertrophied hearts showed a marked decrease in the concentration of 100,000-D protein compared with the sham-operated hearts, while the density of the $\mathrm{Ca}^{2+}$-ATPase protein in the fetal SR was similar to that in the adult SR (Fig. 7). $\mathrm{Ca}^{2+}$ uptake by SR was determined in the presence of ATP and oxalate. $\mathrm{Ca}^{2+}$ uptake was linear up to 5 $\mathrm{min}$, and the value at $5 \mathrm{~min}$ was used to calculate the rate of $\mathrm{Ca}^{2+}$ uptake. The rate of $\mathrm{Ca}^{2+}$ uptake by SR in the hypertrophied hearts (76 $\pm 5 \mathrm{nmol} / \mathrm{mg}$ protein per min) was significantly less than that in the sham-operated hearts $(105 \pm 6$ $\mathrm{nmol} / \mathrm{mg}$ protein per $\mathrm{min})$, while that in the fetal hearts $(96 \pm 5$ $\mathrm{nmol} / \mathrm{mg}$ protein per min) was not different from that in the adult hearts $(102 \pm 7 \mathrm{nmol} / \mathrm{mg}$ protein per min; Table I).

\section{Discussion}

We isolated and sequenced a 2.3-kb cDNA clone encoding a $\mathrm{Ca}^{2+}$-ATPase of rat cardiac SR. Significant homology was recognized between rat cardiac and rabbit slow-twitch skeletal

A

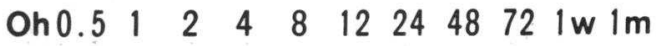
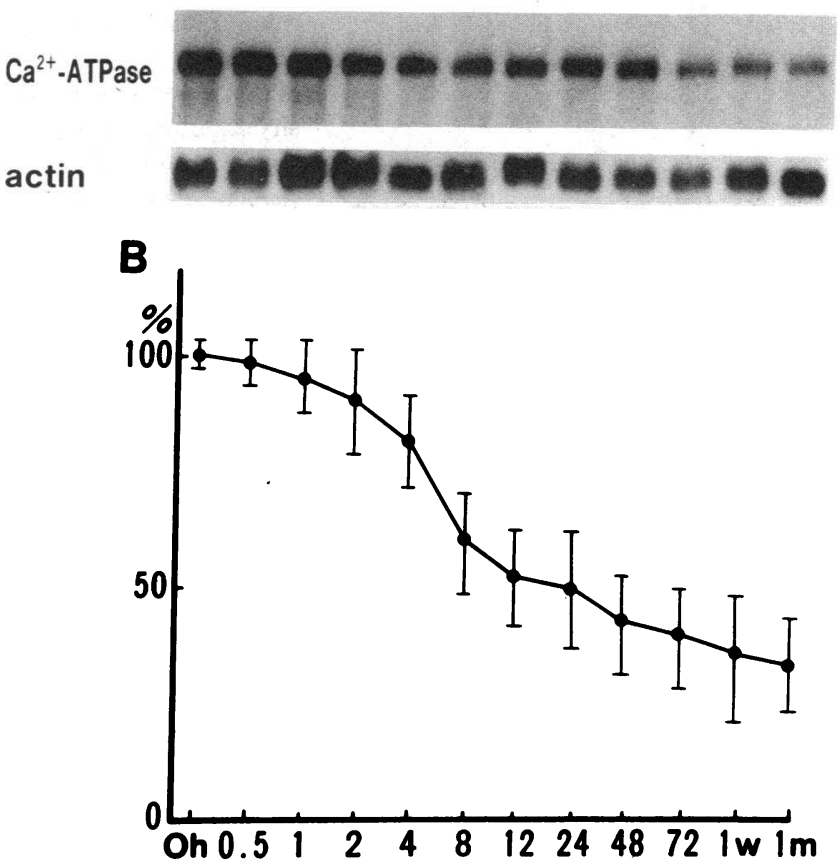

C

Oh $8 \quad 24$ Iw Im

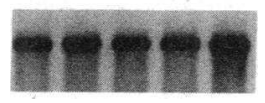

Figure 5. Northern blot analysis of $\mathrm{Ca}^{2+}$-ATPase in pressure overload cardiac hypertrophy. $(A)$ The aorta of male Wistar rats was constricted with a hemoclip. The rats were killed at the indicated times $(0,0.5,2,4,8,12,24,48$, and $72 \mathrm{~h}, 1 \mathrm{wk}$, and $1 \mathrm{mo})$ after the operation and RNA was extracted from the hearts. $3 \mu \mathrm{g}$ of poly $\left(\mathrm{A}^{+}\right) \mathrm{RNA}$ was separated on $1.2 \%$ agarose gel, blotted on nylon membrane, and hybridized with the Eco RI-Eco RI 2.3-kb fragment (pHA6). The membranes were exposed to $\mathrm{x}$-ray film for $24 \mathrm{~h}$ at $-70^{\circ} \mathrm{C}$ with intensifying screen (top). The same RNA blot was sequentially hybridized with mouse $\alpha$-actin cDNA probe to show the integrity of RNA samples (bottom). (B) Relative amounts of $\mathrm{Ca}^{2+}$-ATPase expression were determined by soft laser density scanning. Values are expressed as mean \pm SEM percent of sham control from four separate experiments. $(C)$ The pHA6 cDNA clone was hybridized with the hindlimb muscle RNAs, which were extracted from control rats and pressure-overloaded for 8 and $24 \mathrm{~h}, 1 \mathrm{wk}$, and $1 \mathrm{mo}$. 


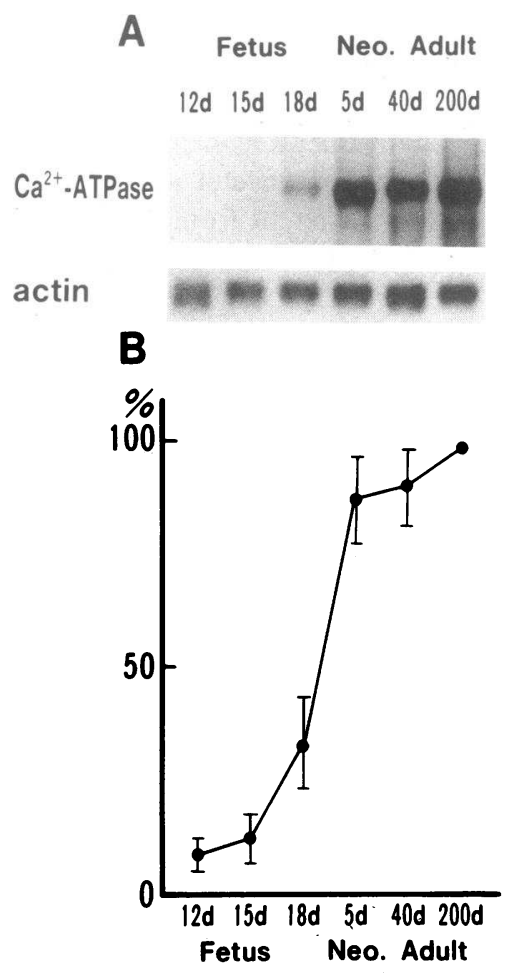

muscle $\mathrm{Ca}^{2+}$-ATPase, whereas the homology between cardiac and fast-twitch skeletal $\mathrm{Ca}^{2+}$-ATPase was relatively low. The mRNA and protein levels of cardiac $\mathrm{Ca}^{2+}$-ATPase decreased by pressure overload. In the developmental stage, the mRNA levels of $\mathrm{Ca}^{2+}$-ATPase and the yields of SR fractions were quite low in the fetal period and steeply increased around birth.

Sequence analyses showed the striking homology, including the $3^{\prime}$ untranslated region, between cardiac and slow-twitch skeletal muscle $\mathrm{Ca}^{2+}$-ATPase despite the species difference. Many reports showed the similarities between cardiac and slow-twitch skeletal muscle $\mathrm{Ca}^{2+}$-ATPase, in their concentration in SR (25), its $\mathrm{Ca}^{2+}$ transport activity, lower ATPase activity (26), and the existence of the regulatory protein, phospholamban (27). MacLennan et al. suggested the identity between cardiac and slow-twitch muscle $\mathrm{Ca}^{2+}$-ATPase from the same restriction endonuclease map and partial sequence analysis $(16,17)$. The present result supports these observations and furthermore shows that the $\mathrm{Ca}^{2+}$-ATPase gene is highly conserved throughout evolution.

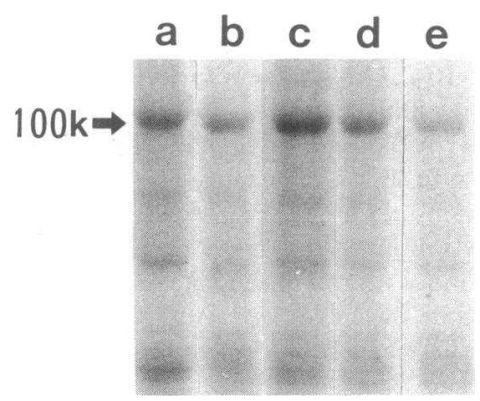

Figure 7. PAGE of SR fractions from the normal adult, fetal, and pressureoverloaded hearts. $30 \mu \mathrm{g}$ of SR fractions from the $40-d-$ old adult $(a)$, fetal $(b)$, sham-operated $(c)$, and pressure-overloaded hearts (2 wk $[d]$ and $1 \mathrm{mo}[e])$ were separated by gel electrophoresis according to the method of Laemmli (22) and stained by Coomasie blue. $100 \mathrm{~K}$,

$100,000 \mathrm{D}$.
Table I. Yield of SR Fractions, $C a^{2+}-$ ATPase Content, and $C A^{2+}$ Uptake

$\left.\begin{array}{lccc}\hline & \text { SR yield } & \begin{array}{c}\mathrm{Ca}^{2+} \text {-ATPase } \\ \text { content }\end{array} & \mathrm{Ca}^{2+} \text { uptake } \\ \hline & m g / g & \% & n m o l / m g \text { per min } \\ \text { Control } & 0.84 \pm 0.10 & 100 & 102 \pm 7 \\ \text { Sham } & 0.90 \pm 0.12 \\ \text { 2 wk after banding } & 0.89 \pm 0.10 \\ \text { 1 mo after banding } & 0.94 \pm 0.16 \\ \text { 15-d fetus } & 0.12 \pm 0.08\end{array}\right] * \begin{array}{cc}112 \pm 10 \\ \end{array}$

$\mathrm{Ca}^{2+}$-ATPase content was assessed by measuring the density of the protein band corresponding to the $100,000-\mathrm{D} \mathrm{Ca}^{2+}$-ATPase protein by a densitometric scanner. Results are the mean \pm SEM percent of control. Control, 40-d-old Wistar rats; sham, rats sacrificed 1 mo after sham operation; 2 wk and 1 mo after banding, rats sacrificed 2 wk or 1 mo after aortic banding, respectively, mean \pm SEM.

${ }^{*} P<0.01,{ }^{\ddagger} P<0.05$.

In pressure overload-induced hypertrophy, there is now much evidence that not only contraction force but also myocardial relaxation are impaired (4-8). Gwathmey and Morgan reported that the hypertrophied myocardium demonstrated a prolonged duration of isometric contraction that correlated with a similar prolongation of the calcium transient. They interpreted that the rate of sequestration and perhaps release of calcium by intracellular stores was decreased in the hypertrophied hearts (10). There have been many studies on the SR function in states of cardiac hypertrophy. Although SR function was dependent on the species and ages of the experimental animals, or the duration and the degree of pressure overload, most studies showed the depression in calcium uptake and calcium ATPase of SR in the hypertrophied hearts (11-13, 28, 29). Suko et al. showed the reduced calcium uptake and $\mathrm{Ca}^{2+}$ ATPase in microsomes prepared from calf right ventricles with 6- to 8-wk pulmonary hypertension (11). Lamers and Stinis reported a significant reduction of microsomal $\mathrm{Ca}^{2+}$ uptake in rabbit hearts by aortic constriction for $1 \mathrm{mo}$ (29). In this study we also showed that $\mathrm{Ca}^{2+}$ uptake by SR was decreased by pressure overload for $1 \mathrm{mo}$ in parallel to a decrease in the content of $\mathrm{Ca}^{2+}$-ATPase protein. Lamers and Stinis also reported that phosphorylation of the microsomes by excess exogenous cAMP did not correct the decrease of $\mathrm{Ca}^{2+}$ uptake in the hypertrophied hearts. These results and observations suggest that the abnormality of $\mathrm{Ca}^{2+}$ metabolism might be due to a reduced number of functional $\mathrm{Ca}^{2+}$-ATPase molecules per unit of membrane. The mRNA levels of $\mathrm{Ca}^{2+}$-ATPase decreased from $4 \mathrm{~h}$ after aortic banding and gradually progressed to become $32 \%$ at 1 mo compared with those of sham-operated animals. The protein content of $\mathrm{Ca}^{2+}$-ATPase decreased to $65 \%$ of sham operation by pressure overload for $1 \mathrm{mo}$. The discrepancy between mRNA and protein-decreased levels of $\mathrm{Ca}^{2+}$-ATPase might imply translational or posttranslational regulation of $\mathrm{Ca}^{2+}$-ATPase in cardiac hypertrophy. Again, if the $\mathrm{Ca}^{2+}$-ATPase protein had a long half-life, the discrepancy might be due to the differences between the half-lives of the mRNA and protein. However, since the mRNA levels decreased markedly, the reduction of the $\mathrm{Ca}^{2+}$-ATPase molecule at the pretranslational level might be one of the major reasons for the decrease of the $\mathrm{Ca}^{2+}$-ATPase protein and its decrease 
might be the molecular mechanism for the impaired sequestration of intracellular $\mathrm{Ca}^{2+}$ in hypertrophied hearts.

The expression of $\mathrm{Ca}^{2+}$-ATPase was also regulated during the developmental stage at the pretranslational level. The mRNA levels of $\mathrm{Ca}^{2+}$-ATPase were significantly low in the fetus and steeply increased from $2 \mathrm{~d}$ before birth. Although the protein contents of $\mathrm{Ca}^{2+}$-ATPase and $\mathrm{Ca}^{2+}$ uptake per SR were not changed between the adult and the fetus, the yield of SR fraction was quite reduced in the fetus. Fabiato and Fabiato reported the changes in $\mathrm{Ca}^{2+}$-stimulated $\mathrm{Ca}^{2+}$ release between embryonic and neonatal rat ventricle, and they attributed this change to the sudden maturation of the $\mathrm{Ca}^{2+}$ transport by the $\mathrm{SR}$ around birth (30). In morphometrical studies the SR fractions in the fetal hearts were reported to be less than in the adult hearts (31). Nakanishi and Jarmakani reported that the yield of the SR protein in the fetus was significantly less than in the newborn and the adult, and that the relative value of $\mathrm{Ca}^{2+}$ uptake by SR per gram of muscle in the fetus was $17 \%$ of that in the adult (14). They also observed that the resting tension, half time to relaxation, and cytosolic $\mathrm{Ca}^{2+}$ were increased in the fetus, and they speculated that an age-related change in myocardial contractility is due to the differences in the relative capability of the $\mathrm{Ca}^{2+}$-releasing system and the $\mathrm{Ca}^{2+}$-sequestering system as well as myofibrillar content and ATPase activity. Taken together with the present results and these observations, the decreased $\mathrm{Ca}^{2+}$ sequestration and subsequent impaired relaxation of the fetus heart were determined, at least in part, by the decrease in the expression of $\mathrm{Ca}^{2+}$-ATPase of SR at the pretranslational level.

Quite recently it was demonstrated that the mRNA coding for the $\mathrm{Ca}^{2+}$-ATPase of rat cardiac SR is highly influenced by thyroid hormone (32). Although it remains to be proven whether changes in the $\mathrm{Ca}^{2+}$-ATPase mRNA levels are due to changes in transcriptional rate or in mRNA stability, it was demonstrated in the present study that the cardiac $\mathrm{Ca}^{2+}$-ATPase was also regulated by pressure overload and developmental stage at the mRNA level. Since the mRNA levels of $\mathrm{Ca}^{2+}$-ATPase in the skeletal muscle did not change by aortic constriction, the decrease of $\mathrm{Ca}^{2+}$-ATPase mRNA levels in hypertrophied hearts might be due to hemodynamic overload but not humoral factors. Further work is needed, however, to elucidate the precise molecular mechanisms of $\mathrm{Ca}^{2+}$-ATPase gene regulation.

\section{Acknowledgments}

We are grateful to Dr. D. H. MacLennan for a generous gift of the rabbit $\mathrm{Ca}^{2+}$-ATPase cDNA clone, to Dr. Toshio Nakanishi, Tokyo Women's Medical College, for his advice in analysis of SR proteins, and to Miss Kazue Minamisako for her excellent technical assistance.

This investigation was supported by a grant-in-aid for scientific research and developmental scientific research from the Ministry of Education, Science and Culture, a grant for cardiomyopathy from the Ministry of Health and Welfare, and a grant from the research program on cell calcium signals in the cardiovascular system, Japan.

\section{References}

1. Fabiato, A., and F. Fabiato. 1979. Calcium and cardiac excitation-contraction coupling. Annu. Rev. Physiol. 41:473-484.

2. Tada, M., T. Yamamoto, and Y. Tonomura. 1978. Molecular mechanism of active calcium transport by sarcoplasmic reticulum. Physiol. Rev. 58:1-79.
3. MacLennan, D., and P. C. Holland. 1975. Calcium transport in sarcoplasmic reticulum. Annu. Rev. Biophys. Bioeng. 4:377-404.

4. Alpert, N. R., and L. A. Mulieri. 1982. Heat, mechanics, and myosin ATPase in normal and hypertrophied heart muscle. Fed. Proc. 41:192-198.

5. Hamrell, B., and N. R. Alpert. 1977. The mechanical characteristics of hypertrophied rabbit cardiac muscle in the absence of congestive heart failure. Circ. Res: 40:20-25.

6. Grossman, W., and L. P. McLaurin. 1976. Diastolic properties of the left ventricle. Ann. Intern. Med. 84:316-326.

7. Eichhorn, P., J. Grimm, R. Koch, O. Hess, J. Carroll, and H. P. Krayenbuehl. 1982. Left ventricular relaxation in patients with left ventricular hypertrophy secondary to aortic valve disease. Circulation. 65:1395-1420.

8. Lorell, B. H., W. J. Paulus, W. Grossman, J. Wynne, P. F. Cohn, and E. Braunwald. 1980. Improved diastolic function and systolic performance in hypertrophic cardiomyopathy after nifedipine. $N$. Engl. J. Med. 303:801-803.

9. Schwartz, K., Y. Lecarpentier, J. L. Martin, A.-M. Lompre, J.-J. Mercadier, and B. Swynghedaw. 1981. Myosin isoenzymic distribution correlates with speed of myocardial contraction. J. Mol. Cell. Cardiol. 77:220-234.

10. Gwathmey, J. K., and J. P. Morgan. 1985. Altered calcium handling in experimental pressure-overload hypertrophy in the ferret. Circ. Res. 57:836-843.

11. Suko, J., J. H. K. Vogel, and C. A. Chidsey. 1970. Intracellular calcium and myocardial contractility. III. Reduced calcium uptake and ATPase of the sarcoplasmic reticulum fraction prepared from chronically failing calf hearts. Circ. Res. 27:235-247.

12. Sordahl, L. A., W. B. McCollum, W. G. Wood, and A. Schwartz. 1973. Mitochondria and sarcoplasmic reticulum function in cardiac hypertrophy and failure. Am. J. Physiol. 224:497-502.

13. Ito, Y., J. Suko, and C. A. Chidsey. 1974. Intracellular calcium and myocardial contractility. V. Calcium uptake of sarcoplasmic reticulum fractions in hypertrophied and failing rabbit hearts. J. Mol. Cell. Cardiol. 6:237-247.

14. Nakanishi, T., and J. M. Jarmakani. 1984. Developmental changes in myocardial mechanical function and subcellular organelles. Am. J. Physiol. 246:H615-H625.

15. MacLennan, D. H., C. J. Brandl, B. Korczak, and M. Green. 1985. Amino-acid sequence of a $\mathrm{Ca}^{2+}+\mathrm{Mg}^{2+}$-dependent ATPase from rabbit muscle sarcoplasmic reticulum, reduced from its complementary DNA sequence. Nature (Lond.). 316:696-700.

16. Brandl, C., N. M. Green, B. Korczak, and D. H. MacLennan. 1986. Two $\mathrm{Ca}^{2+}$-ATPase genes: homologies and mechanistic implications of deduced amino acid sequences. Cell. 44:597-607.

17. Brandl, C. J., S. deLeon, D. R. Martin, and D. H. MacLennan. 1987. Adult forms of the $\mathrm{Ca}^{2+}$-ATPase of sarcoplasmic reticulum: expression in developing skeletal muscle. J. Biol. Chem. 262:37683774.

18. Maniatis, T., E. P. Fritsch, and J. Sambrook. 1982. Molecular Cloning: A Laboratory Manual. Cold Spring Harbor Laboratories, Cold Spring Harbor, NY. 189-195.

19. Sanger, F., S. Nicklen, and A. R. Coulson. 1977. DNA sequencing with chain-terminating inhibitors. Proc. Natl. Acad. Sci. USA. 74:5463-5467.

20. Auffray, C., and F. Rougeon. 1980. Purification of mouse immunoglobulin heavy-chain messenger RNAs from total myeloma tumor RNA. Eur. J. Biochem. 107:303-314.

21. Minty, A. J., M. Caravatti, B. Robert, A. Cohen, P. Daubas, A. Weydert, F. Gros, and M. E. Buckingham. 1981. Mouse actin messenger RNAs. J. Biol. Chem. 256:1008-1014.

22. Laemmli, U. K. 1970. Cleavage of structural proteins during the assembly of the head of bacteriophage T4. Nature (Lond.). 227:680-685.

23. Bers, D. M. 1979. Isolation and characterization of cardiac sarcolemma. Biochim. Biophys. Acta. 555:131-146. 
24. Wharton, C. D., and A. Tzagoloff. 1967. Cytochrome oxidase from beef heart mitochondria. Methods Enzymol. 10:245-250.

25. Affolter, H., M. Chiesi, R. Dabrowska, and E. Carafoli. 1976. Calcium regulation in heart cells: the interaction of mitochondrial and sarcoplasmic reticulum with troponin-bound calcium. Eur. J. Biochem. 67:389-396.

26. Heilmann, C., and D. Pette. 1979. Molecular transformation in sarcoplasmic reticulum of fast-twitch muscle by electro-stimulation. Eur. J. Biochem. 93:437-446.

27. Kirchberger, M. A.; and M. Tada. 1976. Effects of adenosine 3':5'-monophosphate-dependent protein kinase on sarcoplasmic reticulum isolated from cardiac and slow and fast contracting skeletal muscles. J. Biol. Chem. 251:725-729.

28. Limas, C. J., and J. N. Cohn. 1977. Defective calcium transport by cardiac sarcoplasmic reticulum in spontaneously hypertensive rats. Circ. Res. 40(Suppl. I):I-62-I-69.
29. Lamers, J. M. J., and J. T. Stinis. 1979. Defective calcium pump in the sarcoplasmic reticulum of the hypertrophied rabbit heart. Life Sci. 24:2313-2320.

30. Fabiato, A., and F. Fabiato. 1978. Calcium-induced release of calcium from the sarcoplasmic reticulum of skinned cells from adult human, dog, cat, rabbit, rat, and frog hearts and from fetal and newborn rat ventricles. Ann. NY Acad. Sci. 307:491-522.

31. Page, E., and J. L. Buecker. 1981. Development of dyadic junctional complexes between sarcoplasmic reticulum and plasmalemma in rabbit left ventricular myocardial cells: morphometric analysis. Circ. Res. 48:519-522.

32. Rohrer, D., and W. H. Dillmann. 1988. Thyroid hormone markedly increases the mRNA coding for sarcoplasmic reticulum $\mathrm{Ca}^{2+}$-ATPase in the rat heart. J. Biol. Chem. 263:6941-6944. 